\title{
Tattua
}

JOURNAL OF PHILOSOPHY

\section{THE PHILOSOPHICAL FOUNDATION AND PRACTICE OF THE REFORM IN THE CONTEMPORARY CURRICULUM AND INSTRUCTION}

\section{Comparison among the Contemporary Process Philosophy, Systems Philosophy and Genetic Epistemology}

\section{Zhao Heling and Xie Bangxiu Harbin Normal University, China}

"Not all the science is related to philosophy, and not all the philosophy is related to science. However, there does exist some valuable scientific information that can be used as the basis of thoughtful philosophy; and there do exist some philosophical concepts and methods that can constitute an essential condition for the integration of scientific discoveries" (E. Laszlo).

"When oppearing into the arena, thinking will find those explanations as practice" (A.N.Whitehead)

According to China's actual conditions, the reform in China's curriculum and instruction has long been based on the traditional western philosophy. Yet, 
contemporary western philosophy has undergone a fundamental change reflecting the time spirit, which has more concern over the harmony of the world, the subjective initiative of the human beings, and their creative spirit. Therefore, the philosophical foundation of the reform in contemporary curriculum and instruction is undergoing a profound change, and it is the educational researchers' historical duty to elaborate this change clearly and systematically.

Whitehead, Laszlo and Piaget have made irreplaceable contributions to the change in the contemporary philosophy, and their studies have revealed various levels and ways constituting the world, and have profoundly expounded new philosophical and scientific spirit from the viewpoint of different disciplines. In the three of them, Whitehead's (A.N.Whitehead, 1861-1947) academic career was earlier than Piaget's (J. Piaget, 1896-1980), and Laszlo (Ervin Laszlo, 1932 -) was the latest. Therefore, we can see the concern over Whitehead's books in Jean Piaget's works, and in the writings of Laszlo the quotation from Whitehead and Piaget can often be seen. By comparing their points of view, we can clearly know and understand the spirit of contemporary philosophy, and further, its profound impact upon the contemporary curriculum reform.

\section{The curriculum and instruction from the perspective of traditional philosophy}

During a period of time, the philosophical foundation of the systems of liberal arts textbooks in China results from the perspective of traditional philosophy. For instance, in the opening parts, textbooks often talk about the nature of this or (the nature of) that, such as the nature of literature, the nature of history, the nature of psychology, the nature of education, the nature of instruction, etc.. The so-called curriculum and instruction from the perspective of traditional philosophy refers to such paradigm of research.

In general, this kind of philosophy holds that the world is made up of material entity, there must be some links among the inner elements of material entity, and the basic and stable links are thought to be the laws of the happening and development of the substance, and funther to be its nature. Therefore, to reveal the nature of a thing is to reveal its laws of changing. Such is the basic task of a subject as to reveal its object's nature and laws. This way of thinking is very similar to the research of classical physics and natural science.

According to this paradigm, the basic issues that the theory of curriculum and instruction must sfudy have the following characteristics: 


\section{On the subject of curriculum and instruction}

In accordance with the traditional philosophy, curriculum and instruction is generally considered as an entity of things. To explain the nature of curriculum and instruction, their basic elements come first to be considered. Although there still aren't any completely unified ideas, it is generally agreed that such entities as teacher, student, curriculum and teaching material, and teaching methods are essential elements. These are the visible entities, and further research is to observe and describe the relationship between these entities.

Since instruction happens among human beings, in the research on the relationship between the elements in the phenomena of instruction, we should first of all make clear the subject and object. There are two basic observations: Firstly, students are the subject, for all the activities are aimed at students' development, and relatively speaking, all other factors are complementary ones, or in other words, can be referred to as the object. There is a very popular argument, declaring that "students are the subject, while teachers play the leading role", but it is not strict logical judgment, but a kind of intuitive of experience, so that it's not good to make much comments on it. Secondly, both students and teachers are the subject, for they both have their own initiative, each having their own goals and aspirations. They constifute the subject of each other. In short, the two points of view hold that only human can be the subject of the development of feachings, whereas the latter has some changes, that is, human (students and teachers) can become subject conditionally, not absolutely.

\section{On the law of curriculum and instruction and the force behind the development}

Based on such analysis, the nature and the law of the process of instruction are to analyze the relation between subject and object, resulting in such propositions as: (1) the relation between teachers and students: Students must learn curriculum and teaching materials under the guidance of teachers; students must form correct world outlook and moral values under the guidance of teachers. (2) The relation between students and curriculum and teaching materials: (Students must) understand the world and develop their intellectual capacity and abilities by leaming the teaching materials. There may be some more detailed presentation on these basic propositions, such as the relationship between the inspiration of students' enthusiasm to learn and the learning of knowledge, between direct and indirect knowledge, between the learning of knowledge and the development of students' intellectual capacity, etc., which is also a way to reveal the laws of instruction, though the laws are of different levels. 
As the research goes further, the issue of the force of the process of instruction occurs. The contradictions between the known and unknown, namely, the contradictions between the knowledge foundation that students have already owned and the new knowledge that students have to learn, are seen as the force behind the development of curiculum and instruction. Lev Vygotsky's theory on "the nearest development area" is often cited to prove the proposition, which is widely accepted, but this is typical of linear model of the traditional thinking.

\section{The limitations of the traditional philosophy in explaining curriculum and instruction}

The above mentioned is the general situation of the research on issues about curriculum and instruction from the perspective of the traditional philosophy. In the history of the theory of curriculum, for the first time, it constitutes a logically clear framework, in which profound knowledge and penetrating insights from the history of the world educational ideology are absorbed; the phenomena of curriculum and instruction are described systematically, coherently, and theoretically; and thus the foundation of the subject of the theory of curriculum and instruction is laid. This style of the theory of curriculum and instruction is a creative achievement gained by researchers in China. It not only is a contribution in theory, but also plays a positive role in promoting the practice of educational reform in China.

Yet this research is not satisfactory, its main defect is that it has simplified the richness and complexity of phenomena of curriculum and instruction. It has not yef gone beyond the mode of thinking about the causal nexus (cause-effect relationship) between two factors, and it didn't reveal the nature of relations between students' development and the world and the creative features of students' cognitive development. The practice under the guidance of such a curriculum and instruction theory consequentially emphasizes on imparting and mastering the ready-made knowledge, and it pays less attention to students' initiative and creativity. The reason is that it exhibits insufficiency in the philosophical and psychological foundation of the research on curriculum and instruction.

\section{The curriculum and instruction from the perspective of the systems philosophy}

In the 1990s, during which, there also exist studies using systems opproaches to inspecting the phenomena of instruction, such as the study on instructional information theory, and that on cybernetics, etc. I was interested in the American 
systems philosopher E. Laszlo, believing that, by using his systems philosophy to study the phenomena of curriculum and instruction; we can obtain a lot of new understanding and interpretation, and thus enrich the research on the theory of instruction.

Systematic thinking is an ancient way of thinking. The modern system theory is founded on the basis of the development of modern science, with L.V. Bertalantfy as the founder, while Laszlo is the founder of systems philosophy. Laszlo said: in the history of western science, two ways of thinking, the atomistic way and the holistic way, alternatively occur, today we are witnessing the conversion of ways of thinking: converting into the careful, exquisite and holistic theory. Then what is this holistic theory? It is the systems philosophy. According to holistic theory, it is necessary for us to understand not only the elements, but also the relationship between them, as well as the characteristics the integrity performs.

\section{On the subject of curriculum and instruction}

Based on the systems opproaches, it is unnecessary to inspect the fundamentals or the classified relationship between two individual factors of curriculum and instruction, like people do by using the otomistic methods; it is only necessary to make an inspection into the integrity of the elements. It's simply because that the wholeness is not a simple addition of components. Based on such ideas, what the research on curriculum and instruction should pay attention to is to study how the integrity of the interaction of a number of uncertainties performs. For example, the studies on the optimization of instruction and on models of teaching can be regarded as "holistic research, rather than on factor analysis. In fact, it is hard to know for sure how many factors there exist that have influence on instruction, and this is the fundamental defect of the factor-analysis research, yet the advantage of the integral analysis.

According to the ideas of system theory, the subject and object dimidiate thinking mode can no longer work, because the nature of things is not determined by the characteristics of the factors, but by the holistic structural relationship of things. The nature of the holistic structural relationship determines the trend of the development of things. Take the often-mentioned democratic instruction and autocratic instruction as examples, (we can see that) different kinds of structural relationship may result in different effects. Post-modern philosophers criticize the ontology, reasoning that the subiect is not scheduled, but determined by the realistic relationship in the society. Of course, the system theory does not deny individuality and personal independence, but they both must be subordinated to the constraints of the surroundings and of the interrelationship. If the structural relationship was destroyed, and things were in 
a mess, there wouldn't be any achievement in the development of individuality. In fact, without talking about the sociefy, school or teacher, without talking about the rules, systems, disciplines, or ethics, the simple emphasis on sfudent's freedom of individuality is merely a beautiful lie.

\section{On the law of curriculum and instruction and the force behind the development}

The systems philosophy requires revealing the holistic nature of the system, not to isolatedly inspect the causal nexus of factors. Based on the ideas of system theory, the whole world, from the tiny atom to the cosmos, is a large hierarchy composed of numerous subsystems, ranging from those of lower levels to those of higher levels. The large system is isomorphism, which means that all the subsystems share the general characteristics of the system, in other words, sub-systems have the nature and laws of their superior systems. Of course, a certain sub-system has its own unique nature and laws. Laszlo had said: We are firstly a natural system, secondly a living creature, thirdly a human being, fourthly a member of the social and cultural entity, and fifthly a unique individual. That is to say, human being have natural nature in the first place and should follow the order of nature, then come in correct order the characteristics of a living creature, a human being, the society and culture, and a unique individual. In other words, human nature is of multiplicity. The same is true to the nature of curriculum and instruction. The instruction as a system, first of all, has such basic characteristics as holism, duality, constancy (self-maintenance), and reproduction (self-creativity). (Heling Zhao: "On the Characteristics of the System of Instruction", Curriculum, Teaching Materials, \& Pedagogy, 1994). The characteristics at the lowest level are students' individual psychological features. Following this route of methodology, the research on the nature and laws of curriculum and instruction will be greatly enriched.

It is obvious that, by observing the force behind the development of curriculum and instruction from the perspective of system theory, the force is certainly a system, which includes the interaction of individual cognition with that of the history of society, and the agreement and the misplacement of the psychological motivations of both the teacher and the student. All these are the force behind the development of curriculum and instruction, each of which works, though at different levels, in the form of cooperation, for they are interrelated to each other. Therefore, the force behind the development of curriculum and instruction is a structure of hierarchy with a variety of factors promoting the development of curriculum and instruction, which can be referred to as the dynamical system of developing the curriculum and instruction. (Heling Zhao: "The Dynamical Structure of the System of Instruclion", Tang Wenzhong: Theory of Instruction, 1991, 132-135) 
3. The limitations of the ideas of the systems philosophy in explaining curriculum and instruction

The 1970s is the times when the western ways of thinking on science transformed, during which the system theory and systems philosophy rise as a response. It is also the era in which different kinds of post-modernism emerge. But the two don't take the same roule. L.V. Bertalanffy and E.Laszlo have not fully agreed, to some extent disagreed with post-modernism. For instance, in his Introduction to Systems Philosophy, Laszlo said: I can not accept the argument, saying that 'life is that an idiot is telling a story', nor can I think another saying reasonable, which believes that we can find the essence of life and of the world by simply relying on our own experience. In the preface of Laszlo's Introduction to Systems Philosophy, L.V.Bertalanffy has similar arguments, claiming that the system science and philosophy is "contrary to the blind natural laws of the mechanical world outlook and to the process of the world in Shakespeare's stories told by an idiof". Obviously they two are referring to something, for at that time, the propositions "returning to the life world" and "returning to experience" have been widely known. But it cannot be denied that, neither can positive sciences draw a picture of complete world, nor can system sciences. So it is also a kind of bias to regard the words of postmodernism as "idiot" or nonsense. As a matter of fact, the systems philosophy enlightens many post-modern philosophers.

\section{The curriculum and instruction from the perspective of the process philosophy}

Laszlo's systems philosophy benefited from the enlightenment of Whitehead. In his Introduction to Systems Philosophy, Laszlo said: I read through the history of philosophy ... and finally I found Whitehead. In his "organism" philosophy, I believe I have found the answer worthy of sustained thinking. The following is an attempt I make to respond to some basic questions of the theory of curriculum and instruction, using Whitehead's process philosophy.

\section{On the subject of curriculum and instruction}

A Greek philosopher said: It is impossible to walk across the same river twice. Why? Because the river water keeps flowing away, and the water passing here at this moment can never be the same amount of water passing here at another moment, so it can't be the same river at two different moments. By an extension of this logic, everything in the world, physical or mental, keeps changing in the same way. Therefore, the process philosophers believe that the only fundamental exisfence 
in the world is the changing process of things, the world is the process, and the process is the world. The unit constituting the process is called actual entity or event. The collection of all the actual entities at the same time is called the actual world, or the event world. So the world is not a world made up of material substances or of spirit according to traditional philosophy.

In accordance with the process philosophy, different from what most textbooks in China claim, the basic elements of curriculum and instruction are not students, teachers, teaching materials, teaching approaches, etc., but the process of instruction, or various activities or events of instruction. In fact, this is consistent with our experience and obsewation. Instruction is not a physical or mental entity. Isolatedly speaking, such factors alone as students, teachers, teaching materials, or ideas, goals, or methods of instruction, can not constitute instruction. Instruction is a kind of relationship, a kind of interaction between teaching and learning, and can be defined as a kind of bilateral activity in general. Curriculum and instruction has been in constant change down the ages. When it comes to a certain period of time, like the river water, students are moving, and teachers are moving, the constitution of certain specific actual bilateral activities of instruction are temporal, and are unrepetitive events of instruction. That is why we often say that it is impossible to have two exactly the same classes, and even if the students, the teacher and the content of the classes are the same, there aren't any exactly repeated classes. That is what the irreversibility of process discussed in the process philosophy means. So what is eternal? The process of instruction is. Confucius said: Could one but go on and on like this never ceasing day or night. The water flows away instantly, but the process exists day and night. No matter what change may happen, where there is instruction, there is process, there are events. They are the actual entities Whitehead referred to, the final and ultimate constitutional elements of curriculum and instruction.

According to the traditional philosophy, only human can be the subject, and the world relative to human is the object. So, when referring to the subject, textbooks of the theory of curriculum and instruction only mention students, or students and teachers, while textbooks and other non-human elements can only be regarded as the object. The process philosophy also discusses the issue of subject and object, but neither the subject nor the object limits to human, or is preformed. Everything in the world is equal and can be subject and object. The subject and object are interdependent, mutually generated, and mutually prehensive. Therefore, the process philosophy holds pan-subjectivism, that is, "things in reality are the subject when inspected from their own perspectives, yet are the objects when inspected from others' perspectives. Whitehead regarded the dynamic mulual transformation from subject to object, or from objecl to subject as the intendment of the "process". 
Prehension is a key term in the process philosophy. As a means of actual entity, prehension is a concept not only of ontology, but of epistemology and axiology. When claiming that the actual existence of things means to be comprehended by other things, and to comprehend other things so that things can become actual entities and each other's subject or object, it is explaining the significance of prehension in epistemology and axiology. Furthermore, only when there is interrelation among things in the sense of ontology, epistemology and axiology can they become actual entities and mutual subject or object.

Thinking about instruction according to this theory, all the elements associated with the instructional activities may have the quality of subject and object. Not only may students and teachers be subject and object, but teaching materials and approaches, the instructional ideas, goals, methods, etc. may also be subject and object, because they all may have interaction with each other and prehention between each other. However, we are saying that it is possible, not necessary. For all the factors possible to constitute curriculum and instruction, only when they get into the process of instruction and when the mutual prehension occur among them, that is, only when there appears the interrelation among things in the sense of ontology, epistemology and axiology, can they become actual and necessary participants, become actual entities, and become subject and object of the process of instruction. That is why the process philosophy refers to this situation as actual occasion (some translator translated it as "real occasion"). Only when there is actual occasion can there be actual entity and subject-object relationship. In none of the following situations do actual occasions occur, so that none of them can possibly become the subject and object of curriculum and instruction. (The impossible situations are as follows:) In the classroom, the teacher turns a blind eye to students' misbehaviors that should be directed, students are restless and absent-minded, some of the content of the teaching materials is beyond students reach or ignored, and the multi-media instruments are only a display in the classroom.

\section{On the law of curriculum and instruction and the force behind the development}

Whitehead said: "How the actual entities are generated constitute what actual entities are" ... their "existence" is made up of their "generation". This is the "the process principle". As an old Chinese saying goes, "Reap as one has sown." Whitehead's "process principle" seems to be different from it: What is sown is unknown, if melons grow out, melons can be reaped; if beans grow out, beans can be reaped. 
It is a very complex task to understand Whitehead's process principle. A few of his basic terms and the relationship between them can describe this principle in general. One, many and creativity, referred to as the "ultimate categories" by Whitehead, are the basic concepts describing the process principle. The cosmos develops in this way: it turns from one to many, and from many to one; the turning from one to many is called separation, many separations are called being-together; the furning from many to one is called concrescence, and the so-called concrescence is the new one integrated from many being-togethers. The fundamental feature of the process furning "from one to many and from many to one" is "the creative progress". Thus, Whitehead said: Creativity is the ultimate cause behind all the forms. The key words of the process philosophy: actual entity, actual occasion, prehension, and concrescence, are all the creative activities of the process. Because of such creative activities, existence comes into existence, and the cosmos becomes the cosmos. This is like what is said in China's Lao Tzu, Tao Te Ching: "Tao gives birth to one, one gives birth successively to two, two to three, and three to many." Or like what is said in Book of Changes (iching): "The great achievement is that the Sun is brand new every day, and $Y_{i}$ (Changes) means that life goes on and on and new things come continuously into existence."

Then how can we explain the curriculum and the process of instruction with Whitehead's process principles? It is a new problem needing exploring. In my opinion, if all the elements of curriculum and instruction are actual entities, and in the process of practice, there occur relations of actual occasion, prehension, and concrescence, which go on and on in the life circle, then this process is nothing but an endless process of creation.

Laszlo commented on Socratic catechetic method in his The Systems View of The World: According to Plato's view, by means of question asking and answering between each other, the two persons can get closer to the truth; while through their own efforts, any one of them can not get so close to it. The outcome of the debate is never the simple addition of one person's knowledge to another's. What the debate results in is some knowledge neither of them knows in advance, which is impossible for either of them to know through their own efforts. It is impossible for the nature of the entirely made up of the two to revert to the nature owned by the two separate individuals. Doesn't this example demonstrate the creativity of curriculum and instruction? And isn't such situation very common? In fact, as the society is continually developing, the school life may put forward new demands, and the reform in education has never ceased. In schools, every day, teachers are thinking about how to improve the effectiveness of instruction, and students are learning new knowledge. This is the school of life, the life full of creative work. 
Water has potential energy and flows because of the fall. In philosophy, if the world is regarded as the process, then what is the force promoting the process? Newton's world view can not answer this question, because, in his opinion, the world is composed of dead particles, and the force can only come from God. The ancient Greek philosopher Heraclitus (B.C. $504 \sim 501$ ) said that the primitive of the world is fire, but it is too specific. Leibniz said that (the primitive of the world) is monads, but it is too much vitalized. However, the latter two held the organic world view, and Whitehead referred to his (philosophy) as the organic philosophy, claiming that his actual entity is the ultimate existence of the world, as is called in the traditional philosophy the primitive or primordium of the world. Because the nature and essence of actual entity is activity, the force of the process of the world belongs to actual entity.

Based on the concepts of the process philosophy, the force of curriculum and instruction is the various actual entities constituting the process, or the elements that participate in the instructional activities and have activity relations, such as feachers, students, teaching materials, teaching approaches, as well as the instructional ideas, goals, and methods, etc. It is easy to understand that teachers and students (are the force of curriculum and instruction), for they are human beings with the potential initiative and enthusiasm to participate in the activities. But if we look at the issue from the view of ecology, it is not difficult to understand the activity functions of other instructional factors, such as teaching materials, approaches, the instructional ideas, goals, and methods, etc. In fact, Whitehead's philosophy is the most influential theory in modern eco-philosophy. He advised: "(Let's make) farewell to anthropocentrism. Nature has its own intrinsic value independent of the human beings, in which each actual entity is the center of the cosmos respectively, no individual or species has any privileges, and all the actual entities are equal in principle." The egoism of the human species comes from his wrong cognition in ontology. Only when human is free from such errors can he correctly understand his own unique value.

\section{The significance of the process philosophy to curriculum and instruction}

Whitehead said: When appearing into the arena, thinking will find those explanations as practice. This explanation is somewhat universal, for it is an explanation of the structure rather than of the individual." Indeed, Whitehead's philosophy can enhance our level of rational thinking about the phenomena of curriculum and instruction. In this aspect, the American W.E. Doll's A Post-modern Perspective on Curriculum and W:F. Pinar's Autobiography, Politics, and Sexuality, What is Curriculum Theory, and Understanding Curriculum have made achievements that altract the world's 
attention. It should be noted that Whitehead's philosophy is an open philosophy, and many researchers, including Laszlo, have worked on the basis of selection. Here, we should pay special attention to the issue of the relationship of national culture. Whitehead also especially reminded people of noticing own nation's language and knowledge. I agree with this point of view more, for any knowledge has its ethnic, historical and linguistic backgrounds. Any idea of the western world must be translated into own nation's language to be understood, and must be transformed for many times, from literal translation to quotation, and to personal understanding.

\section{Re-discussion on activity teaching}

\section{The history of activity teaching}

This thesis discusses about the issue of "activity teaching" lastly, because contemporary process philosophy can provide a source of new inspiration and interprefation for the theory and practice of activity teaching.

The germination of the idea of activity teaching can be traced to the 17 th century Czech educator Comenius (J. A. Comenius, 1592-1670), who said: "The master does not delay their disciples with the theory, but ask them to do the actual work from the beginning. For example, they learn hardening by hardening, learn sculpturing by sculpturing, learn drawing by drawing, and learn dancing by dancing. So, in school, students should be allowed to learn writing by writing, learn talking by talking, learn singing by singing, and learn reasoning by reasoning, so that the school can become a factory busy with work. All the students who have achievements can experience the truth of an old saying, that is: We have formed ourselves as well as our materials simultaneously". The educational ideology reflected in this sentence can be compared to any theory that is the most advanced today, and what activity teaching pursues is such kind of teaching in general. Activity teaching became the basic idea of the new education movement in countries in Europe and America at the beginning of the last century. But it was not until 1934 when a chapter named "A Campaign of Activity Teaching" was included in The 33" Almanac of the American National Council for Educational Research that the concept "activity teaching" became popular. Since then, both J. Piaget from Switzerland and W. F. Connell, an Australian education historian, have used the concept "activity teaching" to refer to the progressive education movements in history. So, the research of activity teaching has had a history of a century.

Piagef (J. Piaget, 1896-1980), a firm exponent of the activity teaching, published New Methods and Their Psychological Foundation in 1935, in which he has made comments on the activity teaching, and expressed his understanding of the 
scientific rationality of activity teaching. In 1965 he published Educational Science and Kidology re-advocating activity teaching, which was close to the publication of his classic books The Psychology of the Child (1969), Le Structuralism (1968), and The Principles of Genetic Epistemology (1970).

Believing that activity teaching started from Rousseau, Piaget said: "Ever since Rousseau, people began repeating that the child had his/her own actual activities, and education couldn't be successful without really making use of and extending such activities." This formula made Rousseau the Copernicus in education. Then, people came to realize that "intelligence is a real and constructive activity, and personality and will are sorts of sustained and dogged creation." This became the soul of activity teaching in the past century. Piaget's New Methods, and Their Psychological Foundation published in 1935 was not very influential. It was not until the mid and late 1950s that Piaget's studies caught worldwide attention. In 1959, the International Conference on 'Public Education' suggested countries all over the world that "in order to promote primary school students' interest in learning science and technology, it be appropriate for them to adopt activity approaches suitable for cultivating the spirit of experiment."

Making a comprehensive view of activity feaching for over a century, although the research named as activity feaching doesn't seem to have a growing history, the soul of activity teaching can be found here and there in the educational reforms in different countries. Well, what is Piaget's contribution to activity teaching? In brief, with his philosophical constructivism, genetic epistemology and consfructivist kidology, Piaget has laid a solid foundation for the activity teaching he advocated. No other theory of curriculum and instruction has so solid theoretical foundation and so farranging practical basis. Following Piaget, the word "construct" became the most popular term in the international philosophical and sociological areas. As for the research of the theory of curriculum and instruction, such propositions have been widely disseminated as "students develop in and through activities" and "students' development is a constant process of self-creation". Today, we recognize the values and constructivist features of Whitehead's process philosophy through Piaget.

\section{Whitehead, Laszlo and Piaget and Activity Instruction}

The time that Whitehead, Laszlo, and Piaget lived was interlaced, but their academic fields and interests were different. What Whitehead thought about is the nature of the world, from the big cosmos to the small particles, including Heaven, Earth, Mankind, and God, having outlined a picture of the endless succession of the organic world. Laszlo further structured the picture, presented the systematic structure of the world, and enabled people to understand the developing laws of the world 
system. And Piaget did the new work in the man's soul, brought to light relations between human and the world, the development of man's cognition, and the law of children's physical and mental development. Between Whitehead and Piaget, Laszlo clearly stated that, inspired by Whitehead, he has reified and systematized Whitehead's cosmology on the one hand, and on the other hand, while expounding the mental and cognitive systems, he has made use of Piaget's research conclusions as evidence. For example, while discussing the law of "self-maintenance of the natural systems in the changing environment", he said, Piaget pointed out that in the process of personal development and maturation, the perception "scheme" and "logic" is actually in development. ... ... the "balancing" process of selfadjusting ......the absorption and acquisition of new concepts; while discussing that "the natural system creates itself", he said, Piaget told us that the human cognitive structure is the result of the continuous creation beginning from the initial experience in the infancy. Therefore, there exists miraculous compatibility and privity among the theories of Whitehead, Laszlo, and Piaget. With regard to the research of the theory of curriculum and instruction, what's more important is that they presented a common reason: the development of the world, the physical nature, the society, and the human beings, the development and growth of us ourselves, the children, the students and the teachers are the processes of creation and selfcreation, and the processes of construction and self-construction.

More than 20 years ago, when I had a set of instructional modes called "ActivityTraining" based on Piaget's construclivist epistemology and psychology, and completed the experimental work 4 years later, I wrote the following passage: "People may ask: What is your theoretical base? is it the theory of Piaget or Bruner? Is it epistemology, anthropology, or the intelligence theory? Our answer is: it is none of these but God's enlight, and this God is the time spirit. Have you not seen that no matter whether it is epistemology or psychology, pedagogy or anthropology, the history of psychology or the history of intelligence, the research in these areas tend to have o common conclusion: the human cognition and intelligence is the activity of creativity, its development is determined by the level of human practice or activity, and this is a spirit of our time." Today, when we rediscover the value of Whitehead's process philosophy, we believe even more in this time spirit.

\section{Reference}

01. Confucius, The Anolects, Wordworth, 1996.

02. Connell, W.F., A History of Education in the Twentieth Century World, 1983.

03. Doll, W.E., A Post-Modern Perspective on Curruculum, 1993. 
04. Heling, Zhao, Development, Creation and Activity, 2001.

05. Heling, Zhao, The Textual Criticism on the Mistory of Activity Teaching, 2000.

06. Heling, Zhao, Theory and Experiment of Activity: Training Teaching, 1996.

07. Lao Tzu, Tao Te Ching, Wordworth, 1997.

08. Laszlo, E., Introduction to Systems Philosophy, Toward a New Paradigm of Contemporany Thought, 1972.

09. Laszlo, E., The Systems View of the World, The Nolural Philosophy of Developments in the Sciences, Wordworth, 1978.

10. McDoniel, J., What is Process Thought? 2008.

11. Piaget, J., Le Structuralisme, 1979.

12. Pioget, J., The Principles of Genelic Epistemology, 1972.

13. Pinar, William F., (et al), Understanding Curriculum, 2000.

14. Pinar, William F., What is Curriculum Theory, 2004.

15. Whitehead, Alfred North, Fundamental Principles in Education, 1919.

16. Whitehead, Alfred North, Modes Of thought, 1938.

17. Whitehead, Alfred North, Process and Reality: An Essay in Cosmology, 1929. 